\title{
Review
}

\section{Mechanisms of transcriptional regulation by p53}

\author{
Kelly D Sullivan ${ }^{1,2}$, Matthew D Galbraith ${ }^{1,2}$, Zdenek Andrysik ${ }^{1,2}$ and Joaquin M Espinosa ${ }^{\star, 1,2,3}$
}

p53 is a transcription factor that suppresses tumor growth through regulation of dozens of target genes with diverse biological functions. The activity of this master transcription factor is inactivated in nearly all tumors, either by mutations in the TP53 locus or by oncogenic events that decrease the activity of the wild-type protein, such as overexpression of the p53 repressor MDM2. However, despite decades of intensive research, our collective understanding of the p53 signaling cascade remains incomplete. In this review, we focus on recent advances in our understanding of mechanisms of p53-dependent transcriptional control as they relate to five key areas: (1) the functionally distinct $\mathrm{N}$-terminal transactivation domains, (2) the diverse regulatory roles of its C-terminal domain, (3) evidence that p53 is solely a direct transcriptional activator, not a direct repressor, (4) the ability of p53 to recognize many of its enhancers across diverse chromatin environments, and (5) mechanisms that modify the p53-dependent transcriptional program in a context-dependent manner.

Cell Death and Differentiation (2018) 25, 133-143; doi:10.1038/cdd.2017.174; published online 10 November 2017

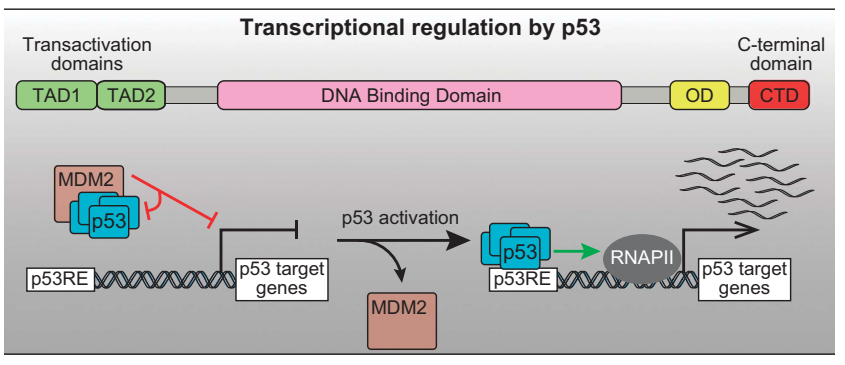

Facts

Graphical Abstract

- p53 regulates transcription via two functionally specialized transactivation domains.

- p53 recognizes its DNA response elements by an elaborate mechanism involving a sequence-specific core DNAbinding domain and the regulatory $\mathrm{C}$-terminal domain.

- p53 is solely a transcriptional activator, with gene repression downstream of p53 activation being indirect.

- p53 overrides epigenetic regulatory landscapes to bind a common set of enhancers in a variety of cellular contexts.

- The overall output of the p53 transcriptional program is strongly qualified by cellular context via enhancer licensing, core promoter responsiveness, and chromatin architecture.

\section{Open questions}

- How does p53 function in different cells and tissues within the human body?

- To what degree is p53 function modulated in humans by variables such as sex, age, metabolic state and common physiological changes?
- What are the key p53 target genes and effector pathways mediating tumor suppression in different human tissues?

- Can p53 tumor suppressive function be enhanced for therapeutic purposes via manipulation of its cofactors, target gene activity or chromatin context?

Although the tumor suppressor p53 was first characterized as a transcription factor more than 25 years ago, ${ }^{1-5}$ there are still many unresolved questions about its mechanism of action. The 553 polypeptide contains several functional domains that work coordinately, in a context-dependent fashion, to achieve DNA binding and transactivation. These include the composite $\mathrm{N}$-terminal transactivation domains (TAD1 and TAD2, residues $\sim 1-40$ and $\sim 40-61$, respectively), the proline rich domain (PR, 64-92), the central DNA-binding domain (DBD, residues $\sim 100-300$ ), the oligomerization domain (OD, residues 323-355), and the unstructured C-terminal domain (CTD, residues 364-393) (Figure 1). p53 functions as a tetramer to recognize p53 response elements (p53REs) consisting of two copies of a 10 base pair motif with the consensus $5^{\prime}$-PuPuPuC(A/T)(T/A)GPyPyPy- $3{ }^{\prime} .{ }^{6}$ p53 activity as a transcription factor is repressed by MDM2, which masks the $\mathrm{N}$-terminal region of $\mathrm{p} 53$ and also promotes p53 degradation via ubiquitination. ${ }^{7-9}$ The related protein MDM4 also blocks p53 transactivation, albeit without promoting p53 degradation. ${ }^{10,11}$ Upon myriad cellular stress stimuli, the repressive effects of MDM2 and MDM4 can be relieved by diverse signaling pathways that prevent the physical interaction between p53 and its repressors (reviewed in ref. 12). Here we will focus mostly on discoveries from the past five years that demonstrate: (1) functional specialization of the two TADs during transactivation and tumor suppression; (2) multiple regulatory functions of the CTD; (3) p53 is not a direct repressor of transcription; and (4) p53 employs an

${ }^{1}$ Department of Pharmacology, University of Colorado School of Medicine, Aurora, CO 80045, USA; ${ }^{2}$ Linda Crnic Institute for Down Syndrome, University of Colorado School of Medicine, Aurora, CO 80045, USA and ${ }^{3}$ Department of Molecular, Cellular and Developmental Biology, University of Colorado Boulder, Boulder, CO 80203, USA ${ }^{*}$ Corresponding author: J Espinosa, Department of Pharmacology University of Colorado School of Medicine, 12800 E 19th Ave., Aurora, CO 80045, USA. Tel: +303 724 9907; Fax: 303724 5741; E-mail: joaquin.espinosa@ucdenver.edu

Received 26.5.17; revised 25.8.17; accepted 31.8.17; Edited by F Pentimalli; published online 10.11.17 


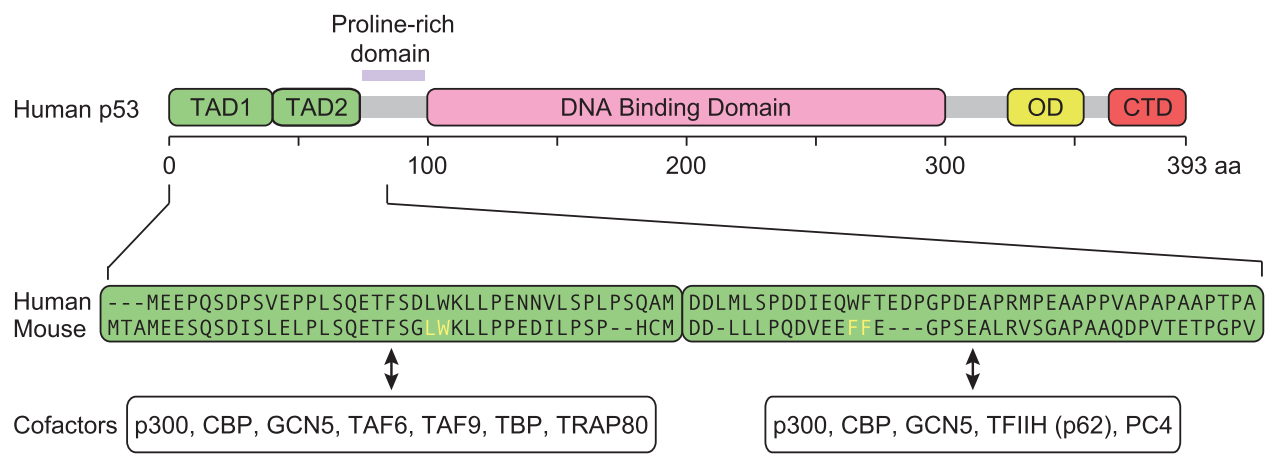

Figure 1 Schematic of p53 protein domain organization. (Top) Transactivation domains (TADs) 1 and 2 are indicated in green, DNA binding domain in pink, oligomerization domain (OD) in yellow, and C-terminal domain (CTD) in red. (Bottom) Primary amino acid sequences for TAD1 and TAD2 in both human and mouse. Residues altered in mouse models of TAD inactivation indicated in yellow. Known transcriptional cofactors are listed below the TAD with which they associate

unsophisticated enhancer logic. Finally, we discuss regulatory mechanisms that modify the p53 transcriptional program in a context-dependent fashion.

\section{The p53 Transactivation Domains: When Having Two is More Robust}

In 1990, Fields and Jang employed the two-hybrid technique to demonstrate that the first 73 amino acids of p53 encode a transactivation domain comparable in strength to that of the VP16 herpes virus protein, thus placing this short peptide among the most potent activation domains known. ${ }^{1}$ Later it was shown that the $\mathrm{N}$ terminus contains two autonomous TADs $^{13-15}$ (Figure 1). Recent work by the Attardi group, using mouse models carrying Trp53 alleles with inactivating point mutations in one or both TADs, demonstrated their functional specialization, whereby each TAD is required for transactivation of different target genes and effector pathways. ${ }^{16}$ Several important observations arise from these studies. First, inactivation of both TADs effectively abolishes all p53dependent gene expression changes (both activation and repression) and impairs tumor suppression in mice. ${ }^{16}$ This is a very important result because p53 has been reported to also function as a direct transcriptional repressor ${ }^{17-22}$ and as a mitochondrial apoptotic factor, ${ }^{23}$ yet the contributions of these functions to p53-dependent tumor suppression are undefined. As discussed later, the description of p53 as a direct transcriptional repressor is unfounded, and it is now clear that gene repression downstream of $\mathrm{p} 53$ is indirect. Second, TAD1 plays a predominant role in p53-dependent transactivation over TAD2, and is required for DNA damage-induced G1 arrest and apoptosis, but dispensable for RAS-induced senescence in fibroblasts. ${ }^{16}$ Third, p53 can suppress tumor growth even when only one TAD is inactivated. In fact, TAD1 mutants, despite being highly compromised in terms of transactivation, are still able to suppress tumor growth in cancers of epithelial, mesenchymal, central nervous system, and lymphoid origins. ${ }^{24}$ There are several possible explanations for these results. On one hand, it is possible that tumor suppression is mediated by a select group of target genes that can be activated when either TAD is intact. Indeed, Brady et al. ${ }^{16}$ identified 130 such genes, 14 of which were found to be downregulated in cancer. An alternative explanation is that the tumor suppressive activity of p53 is highly distributed across its vast transcriptional network, where no single target gene or small subset of genes carries a large fraction of the activity, which would explain the tremendous selective advantage conferred by p53 mutations during tumor evolution. Furthermore, this could also explain the evolutionary pressure to split the transactivation function into two domains, which creates a more robust transcription factor. In fact, the $\mathrm{N}$-terminal domain of p53 does not carry any hot-spot mutation sites, whereas mutations in the DBD are much more common. ${ }^{25}$

Diverse transcriptional cofactors have been found to interact with either or both TADs, including subunits of general transcription factors, the Mediator complex, and various histone modifying complexes (reviewed in refs 26-28) (Figure 1). The global contributions of these cofactors to the p53 transcriptional program and tumor suppression remain to be defined, but most likely these cofactors contribute to p53 function in a context-dependent fashion.

\section{The Disordered C-Terminus: One Domain, Many Roles}

The biological role of the p53 CTD remains a subject of much fascinating exploration. Back in 1991, before the identification of the consensus p53RE, Foord and colleagues ${ }^{5}$ mapped p53 DNA-binding activity to the CTD, a conclusion that was driven by the use of non-sequence-specific DNA-binding assays. Remarkably, after the identification of the consensus p53RE and the central DBD, a series of papers described the CTD as an allosteric negative regulator of sequence-specific p53 DNA-binding activity. ${ }^{29,30}$ This model was based on studies showing that truncation of the CTD, interaction with a CTDspecific antibody ( $p A b 421)$, and CTD phosphorylation or acetylation enhanced p53 binding to short oligonucleotides containing p53REs. ${ }^{29-33}$ Experiments showing that short CTD peptides could enhance the 'latent' DNA-binding activity of wild-type $\mathrm{p} 53^{34-36}$ were interpreted as further support. However, a flurry of reports in the 2000's overturned this model, which was driven by artefactual results produced by assays employing short pieces of naked DNA that cannot be bound by full-length $\mathrm{p} 53$. In fact, when the size of the DNA fragment is increased from 25 to $160 \mathrm{bp}$, the binding activity of wild-type 053 increases by several orders of magnitude, and the stimulating effects of CTD modifications disappear. ${ }^{37}$ The 
a

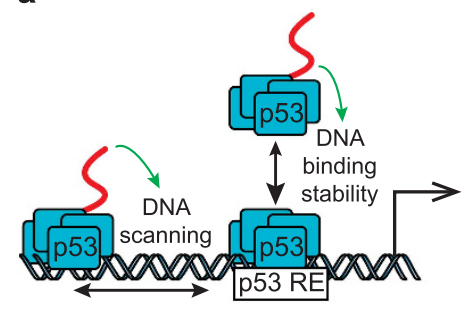

b

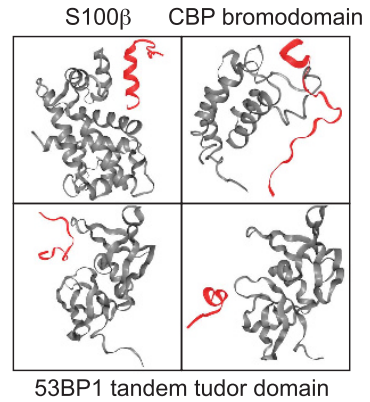

C

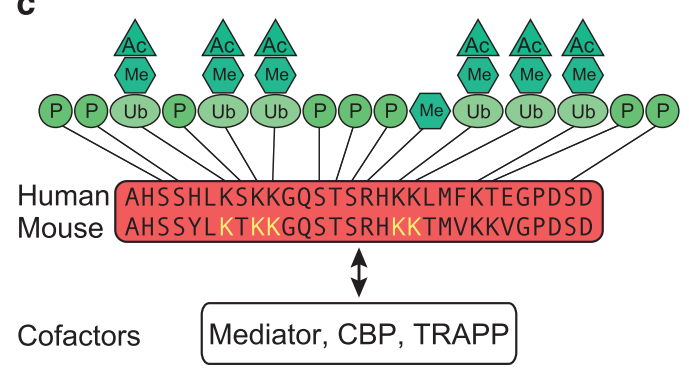

d

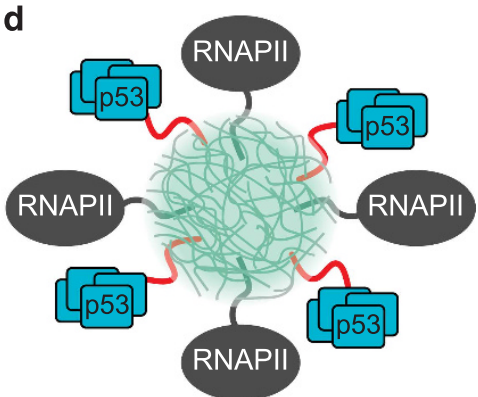

Figure 2 Functions of the p53 C-terminal domain (CTD). (a) The p53 CTD is important for DNA binding. The cartoon depicts the dual roles of the CTD (red) in recognition of the 553 response element (p53RE), by positively influencing scanning along DNA and stability of binding. ${ }^{39,49}$ (b) The p53 CTD is structurally flexible. Representative ribbon structures of alternative conformations adopted by the CTD (red) upon binding to the different partners (gray) $S 100 B^{56}$ the bromodomain of $\mathrm{CBP}^{57}$ and the tandem tudor domain of 53BP1 ${ }^{58}$ (c) The 553 CTD is postranslationally modified. Schematic depicts the primary structure of the CTD with known modifications and sites indicated. Lysine residues altered in mouse models of CTD inactivation highlighted in yellow. CTD-interacting transcriptional cofactors are listed at the bottom. (d) Model of p53 CTD (red) intrinsically disordered domain-mediated aggregation at RNA factories (light green cloud) along with RNA polymerase II (RNAPII, gray). Ac, acetylation; Me, methylation; P, phosphorylation; Ub, ubiquitination

CTD was subsequently shown to have a positive role in sequence-specific binding when the p53RE was present in a long linear, minicircular, or looped conformation. ${ }^{37-40}$ The 'latency' model was further refuted by structural studies showing that CTD truncations do not impact significantly on the structure of the rest of the polypeptide in solution. ${ }^{41}$ Furthermore, the CTD was found to be required for p53dependent transactivation in in vitro transcription assays using nucleosomal templates, ${ }^{37,42}$ and, in a complete reversal of the previous model, cell-permeable CTD peptides were found to actually block DNA binding and transactivation both in vitro and in vivo. ${ }^{42}$ In addition, several studies using ectopically expressed human CTD mutants concluded that the CTD acts as a positive regulator of $\mathrm{p} 53$ function. ${ }^{38,42,43}$

These observations triggered much research activity to elucidate both the molecular mechanism of action and the biological impacts of the CTD. In vitro studies have now demonstrated that the CTD carries non-sequence-specific DNA-binding activity required for sliding along DNA, which facilitates sequence-specific binding by the central DBD $^{39,40,44-47}$ (Figure 2a). This scanning process is likely driven by low-affinity electrostatic interactions between the many lysines in the highly basic CTD, and the acidic DNA phosphate backbone. ${ }^{48}$ Cell-based analysis of human p53 binding to $\sim 600$ known p53REs showed that deletion of the last 30 amino acids $(\Delta 30)$ prevented binding to two thirds of the sequences tested, and decreased its association with the other third. ${ }^{49}$ Furthermore, not a single p53RE was bound by $\triangle 30$ but not wild-type p53, cementing the notion of the CTD as a positive regulator of DNA binding. Sequence analysis of
p53REs differentially impacted by the $\Delta 30$ deletion showed that the CTD is preferentially required for binding to p53REs that deviate from the consensus sequence. ${ }^{49}$ Mechanistically, it was shown that the CTD stabilizes the interaction between the core DBD and DNA, which is accompanied by differences in DNA-induced conformational changes in the DBD. ${ }^{49}$ Thus, the CTD may facilitate an 'induced fit' state to favor a long-lived p53-DNA complex.

Several animal models have been used to test the biological impact of the CTD, with differing results and interpretations. Mouse knock-in models with 6 or 7 lysine-to-arginine replacements in the CTD (6KR and 7KR) did not exhibit any significant phenotype compared to wild-type. ${ }^{50,51}$ These models were generated to test the potential function of lysine acetylation within the CTD, which had been initially proposed to be required for p53 function. Two independent CTD deletion mutants lacking either the last 31 or 24 residues have also been tested. ${ }^{52,53}$ Although p53 $\Delta 31$ mice showed increased p53 activity, this was associated with increased levels of mutant p53 over the wild-type protein, ${ }^{52}$ consistent with biochemical studies demonstrating that the CTD is required for optimal association with MDM2, and p53 degradation. ${ }^{54}$ Thus, on a per molecule basis, p53 $\Delta 31$ is less efficient than wild-type p53 at binding to DNA or activating transcription. The p53 $\Delta 31$ mice exhibited phenotypes that resemble those observed in syndromes caused by telomere shortening, such as aplastic anemia and pulmonary fibrosis. ${ }^{52}$ Intriguingly, the p53 $\Delta 24$ model revealed tissue- and target-gene-specific effects of the CTD. ${ }^{53}$ Homozygous p53 $\Delta 24$ mice died before 14 days of age, accompanied by hematopoietic failure and 
defects in cerebellar development. Further examination revealed that the CTD attenuates p53 activity in the bone marrow and thymus, albeit by different mechanisms. In the bone marrow, p53 $\Delta 24$ mice had increased expression of the p53 target gene Cdkn1a (p21), but not of other canonical p53 targets such as Bbc3 (Puma) and Pmaip1 (Noxa), leading to senescence. In the thymus, the hyperactive p53 $\Delta 24$ induced apoptosis associated with enhanced expression and binding to Puma and Noxa, but not p21, Mdm2, or Tigar. Contrastingly, in the liver, p53 $\Delta 24$ showed intact DNA binding, but decreased transactivation potential, indicative of a positive role for the CTD after DNA binding. In the spleen, p53 $\Delta 24$ behaved similarly as p53 $\Delta 31$, where stabilization of p53 $\Delta 24$ was accompanied by increased expression of several p53 target genes.

How might all these observations be reconciled at the mechanistic level? The p53 CTD is an intrinsically disordered domain (IDD). ${ }^{55}$ IDDs are found in many TFs and RNA regulatory proteins, and, although they do not fold into defined structures, they nonetheless play important biological roles by transitioning between disordered and ordered states, enabling them to interact with a variety of partners with low affinity but high specificity. ${ }^{55}$ Accordingly, the CTD is missing or ill-defined in all published structures of p53 oligomers. However, when complexed with different binding partners, the isolated CTD appears to adopt several different conformations (Figure 2b), forming an $a$-helix when bound to $\mathrm{S} 100$ calcium-binding protein $\mathrm{B}(\mathrm{S} 100 \mathrm{~B}),{ }^{56}$ a $\beta$-turn when bound to the CBP bromodomain, ${ }^{57}$ a U-shape or an $\alpha$-helix when bound to the tandem Tudor domain of 53BP1, ${ }^{58}$ a $\beta$-strand when bound to Sirtuin $2,{ }^{59}$ and no defined secondary structure when bound to the histone methyl-transferase Set $^{60}$ or the cyclin A/CDK2 complex $^{61}$ (reviewed in ${ }^{62}$ ). Therefore, it is likely that, depending on context and availability of different CTD-binding partners, the p53 CTD could confer a wealth of regulatory diversity, affecting p53 function in numerous ways, both positively and negatively. In this regard, it has been shown that the CTD, much like the TADs, can serve as an interaction surface for p53 transcriptional cofactors, including Mediator, CBP, and TRAPP ${ }^{63,64}$ (Figure 2c).

Interestingly, many purified IDDs polymerize into amyloidlike fibers, a property that is thought to drive formation of 'RNA factories' and 'RNA granules' via nucleation of hydrogels that bring together multitudes of proteins into functional subcellular aggregates. ${ }^{65}$ In fact, some IDDs function as transactivation domains by binding to the CTD of RNA polymerase II (RNAPII), which is itself an IDD. ${ }^{66}$ Furthermore, binding of IDDs to the RNAPII CTD is reversible by phosphorylation of the many serines in this repetitive domain, leading to a model whereby RNAPII is recruited to nuclear sites enriched with TFs carrying IDDs, to then be released into an elongationcompetent form by RNAPII CTD-kinases. ${ }^{66}$ Therefore, it is possible to speculate that the p53 CTD can contribute to p53dependent transactivation via targeting to nuclear aggregates containing RNAPII (Figure 2d). Importantly, the CTD is a site of many post-translational modifications, which may impart additional regulatory diversity in a context-dependent fashion (reviewed in ${ }^{67}$ ) (Figure 2c).

In sum, the CTD modulates p53 function as a transcription factor by a combination of mechanisms, including DNA scanning, increased p53-DNA stability via induced fit, cofactor recruitment, and, potentially, nuclear sublocalization into RNA factories.

\section{p53 is the Ultimate Direct Activator, not Really a Direct Repressor}

The fact that $p 53$ regulates a vast gene expression program that involves both mRNA upregulation and downregulation is undisputed. However, the extent to which p53 functions as a direct transcriptional repressor has long been debated. ${ }^{68-72}$ Numerous models for p53-dependent transcriptional repression have been put forth over the years (reviewed $\mathrm{in}^{26}$ ), ranging from p53-dependent recruitment of corepressors, ${ }^{18}$ to inverted (head-to-tail) or imperfect p53REs that impart repressive activities on $\mathrm{p53},{ }^{73,74}$ and 'enhancer competition' by $553 .^{75}$ However, many recent studies have made it clear that the repressive effects of p53 are indirect, and driven by downstream effectors such as p21 (CDKN1A), E2F7, and miRNAs.

Several lines of evidence support the notion of indirect repression. First, using multiplex enhancer-reporter assays, Verfaillie et al. ${ }^{76}$ demonstrated that, among 1500 p53REs bound by 553 in MCF7 cells, none delivered consistent gene repression. By harnessing the power of next-generation sequencing, these assays enable the simultaneous testing of hundreds of enhancer-reporter constructs in a single experiment. Although these constructs may not fully reproduce endogenous chromatin contexts, they nonetheless provide a powerful tool to study TF function. Second, recent meta-analyses of the wealth of available p53-related genomics data revealed that, of the 384 genes identified as repressed by $\mathrm{p} 53$, only 15 were reported as repressed in more than one such study. ${ }^{72}$ When filtering by presence in at least six data sets, 116 genes were identified as directly activated, with not a single gene classified as directly repressed. ${ }^{72}$ Fourth, while defining the impact of inactivating mutations in TAD1/2, Brady et al. ${ }^{16}$ found that all gene expression changes, including repression, required the TADs. Fifth, comparative analysis of bona fide transcriptional activity via Global run-onsequencing (GRO-seq) and RNA profiling data revealed that, although hundreds of genes are downregulated at the steadystate level upon activation of p53 by Nutlin, only four were repressed as defined by GRO-seq. ${ }^{70}$ Unlike measurements of steady-state RNA levels such as RNA-seq, GRO-seq directly measures changes in RNA polymerase activity, thus providing a better tool to study true transcriptional regulation.

One of the first p53 target genes identified was CDKN1A (p21), which encodes a cyclin-dependent kinase (CDK) inhibitor. p21 impedes progression through the cell cycle by blocking CDK-dependent inactivation of the transcriptional repressor $\mathrm{Rb}$, which in turn leads to repression of genes activated by E2F family of $\mathrm{TFs}^{77,78}$ (Figure 3a), including genes previously described as directly repressed by $p 53$, such as $B I R C 5$ (Survivin) and $C D C 25 B-C .^{79}$ Enabling $\mathrm{Rb}$ activity, even in the absence of p53 activation, leads to repression of hundreds of E2F targets that drive cell cycle progression, such as components of the DNA synthesis machinery, cyclins, and histone mRNAs, many of which are consistently downregulated in response to p53 activation. Across multiple cell 
a Indirect transcriptional repression

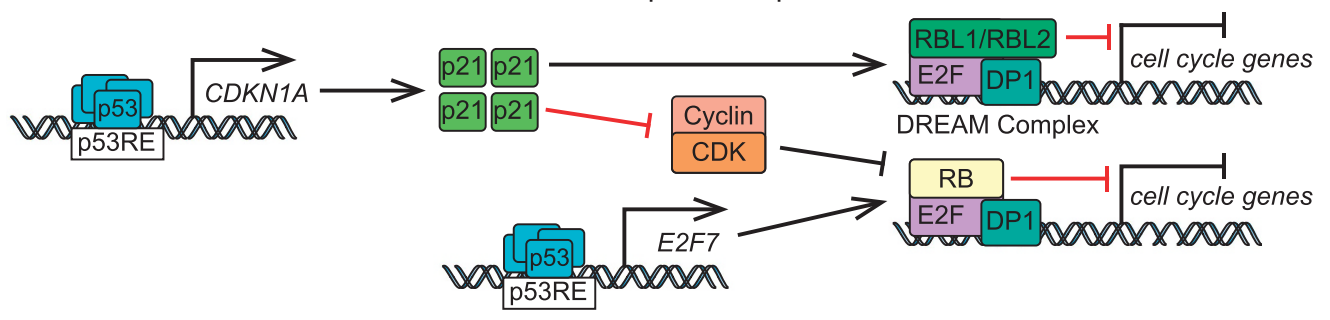

b Indirect post-transcriptional repression

translational repression

or

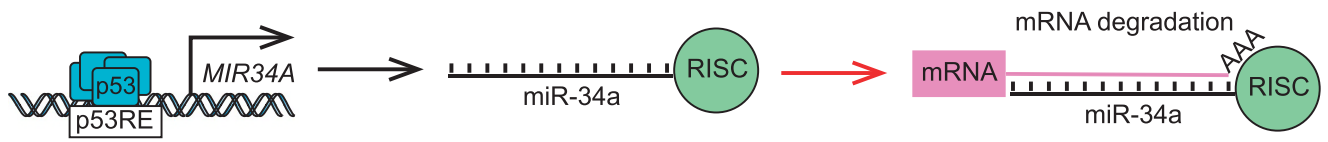

Indirect basal transcriptional repression

C
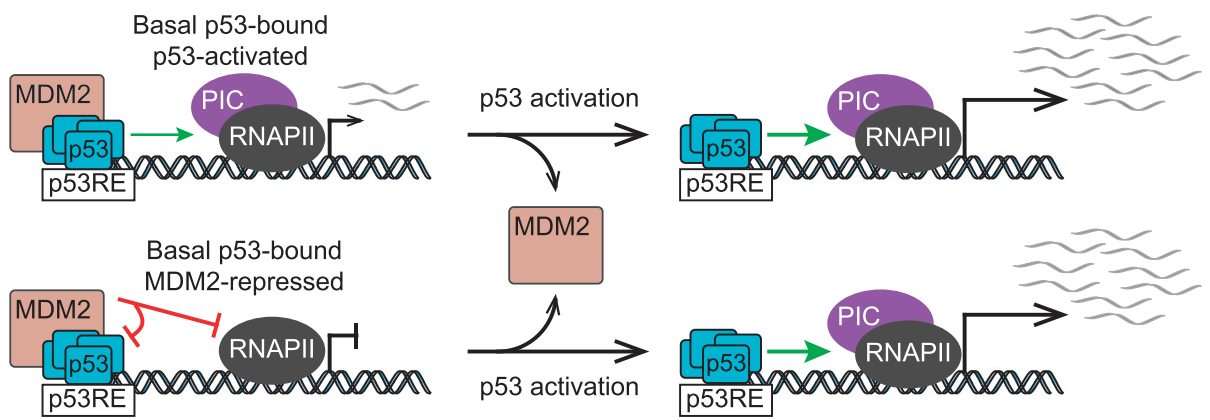

Figure 3 Mechanisms of p53-dependent repression of gene expression. (a) p53 indirectly represses E2F target genes via transactivation of CDKN1A that encodes p21, a CDK inhibitor, leading to transcriptional repression of cell cycle genes by the RB-E2F4 complex and the DREAM complex. ${ }^{79-82}$ In addition, p53 directly transactivates E2F7, a member of the repressive subfamily of E2F transcription factors. ${ }^{83,84}$ (b) p53 post-transcriptionally represses gene expression via microRNAs (miRs) such as miR-34a that can target mRNAs for degradation or translational repression via the RNA-induced silencing complex (RISC). (c) Under basal (non-activated) conditions, even when bound to MDM2, p53 can bind to target genes. Some of these genes are activated by basal p53 (top), while others are repressed by MDM2 (bottom). ${ }^{70}$ p53RE, p53 response element; CDK, cyclindependent kinase; PIC, preinitiation complex; RNAPII, RNA polymerase II

lines and stimuli, p53-dependent repression was shown to be dependent on $\mathrm{p} 21$, via E2F4-Rb repressive complexes. ${ }^{79}$ Recently, the Engeland team also demonstrated that $p 53$ can repress transcription through a p21-dependent switch from MYBL2 (B-Myb), within the activating MMB complex, to RbL1/ RbL2 (p107/p130) to form the repressive DREAM complex at additional cell cycle genes ${ }^{80,81}$ (Figure 3a). More recently, bioinformatics analysis of genome-wide DREAM chromatin binding data and p53-dependent gene expression data revealed $>200$ genes predicted to be regulated by the p53p21-DREAM axis, and many of these genes were experimentally validated. ${ }^{82}$ In addition, p53 can further enable Rbdependent repression by direct transactivation of E2F7, a member of the 'repressive' E2F family of TFs. ${ }^{83,84}$

The p53 network also includes numerous microRNAs that contribute to indirect repression. The first p53-induced microRNA discovered was miR-34a, ${ }^{85-88}$ which contributes to cell cycle arrest via post-transcriptional repression of genes required for cell cycle progression ${ }^{85-88}$ (Figure $3 b$ ). Similarly to p21, miR-34a can reduce CDK activity by targeting the mRNAs of diverse cyclins, thus feeding into the repressive circuit described above. In addition, miR-34a directly represses many mRNAs within the $\mathrm{p} 53$ network by inducing their degradation. Our own analysis of genes downregulated in HCT116 cells following Nutlin treatment revealed that $67 \%$ of them are validated miR-34a targets. ${ }^{70,89}$ Numerous additional miRNAs are directly transactivated by p53 that could contribute to indirect repression of gene expression (reviewed in ref. ${ }^{90}$ ).

As data continues to accumulate that p53 is only an activator, the likelihood that it can also function directly as a repressor becomes vanishingly small. Nonetheless, it is important to note that p53 directly interacts with MDM2, a transcriptional repressor in its own right. Interestingly, comparative GRO-seq analysis of wild-type and p53-null HCT116 cells indicated that p53-MDM2 complexes might directly repress transcription of select p53 targets genes, prior to p53 activation (Figure 3c). Under basal conditions, these genes are downregulated in wild-type cells relative to $p 53^{-/-}$ cells, but are strongly induced upon Nutlin treatment, suggesting that they are repressed by MDM2-bound $\mathrm{p} 53 .^{70}$ Thus, basal amounts of p53 could pre-program the network, priming some target genes and repressing others. Mechanistically, Tjian and colleagues ${ }^{91}$ demonstrated that p53-MDM2 complexes directly repress preinitiation complex (PIC) formation during in vitro transcription assays. They demonstrated 
that MDM2 can repress transcription when independently targeted to DNA using the GAL4 DBD through an inhibitory domain that binds PIC components, such as TBP and TFIIE. Notably, it is known that MDM2 binds to p53REs in a p53dependent manner, and that MDM2 chromatin binding can be disrupted by Nutlin or DNA damage. ${ }^{92}$ MDM2 overexpression was shown to repress some p53 targets, independently of effects on p53 stability or DNA binding, ${ }^{93}$ further supporting the hypothesis that MDM2 can act as a repressor independently of its canonical role in p53 inhibition. ${ }^{94}$

\section{p53, The Unsophisticated Trailblazing Pioneer}

One of the most interesting developments in the recent literature is the realization that p53 employs an unsophisticated enhancer logic that is very uncommon among TFs. ${ }^{76}$ Simply put, p53 recognizes a core set of strong enhancers regardless of cellular context, overriding variations in chromatin landscapes and nucleosome positioning, facilitated by high affinity p53REs that closely match the consensus sequence, and without apparent need of auxiliary transcription factors. However, only few of the bound p53REs deliver transactivation in any given cellular context, with clear cell type-specific variations in the p53 transcriptional program.

p53 binding to chromatin has been studied extensively by means of chromatin immunoprecipitation-based techniques (e.g., ChIP-PET, ChIP-seq) using different cell types and experimental conditions (reviewed in ref. 72). A meta-analysis of 16 different data sets identified $>95,000$ p53 binding events across the human genome, many more than the $\sim 20000$ occurrences of the p53RE. ${ }^{72}$ How many of these thousands of sites are true functional elements driving p53-dependent transcriptional regulation? To answer this, many studies have employed a simple but imperfect 'guilt by association' criterion: if a p53 binding event was observed near a gene whose steady-state mRNA levels change some time after p53 activation, said p53 binding event was deemed functional, and the gene was classified as a 'direct' p53 target. This led to the generation of a catalog of $>3500$ candidate direct targets, whereby as many as $64 \%$ of them were identified in only a single study. ${ }^{72}$ There are caveats to these studies that likely introduced many false positives and false negatives. First, the required distance between a 553 binding event and a putative direct target gene, ranging from $5^{95}$ to $100 \mathrm{~kb},{ }^{96}$ has always been defined arbitrarily. Second, all studies employed relatively late time points (i.e. $>1$ hour) to measure changes in steady-state RNA levels, which unavoidably includes the confounding effects of indirect transcriptional and posttranscriptional regulation. Two updated approaches for identifying functional p53REs have recently been employed to circumvent these limitations: multiplexed enhancer-reporter assays, ${ }^{76}$ and direct measurement of RNA polymerase activity using GRO-seq. ${ }^{70}$

Using complementary high-throughput enhancer-reporter assays and exhaustive analysis of available p53 ChIP-seq data, Verfailies et $a l^{76}$ tested the functionality of $>1500$ genomic sequences found to be bound by p53 via ChIP-seq. Several key observations arose from these efforts: (1) Only $40 \%$ of p53 ChIP-seq peaks are functional in a given cell type; (2) None of the sequences tested conferred reproducible p53- dependent repression; (3) The only sequence motif enriched at functional sites is the consensus p53RE, indicating that p53 acts at enhancers mostly alone, without auxiliary factors; (4) Functional sites consistently harbor a single canonical p53RE, composed of the palindromic repeats required for p53 tetramer binding, without a spacer between the half-sites; (5) Meta-analysis of 15 ChIP-seq data sets derived from 7 different cell types and conditions revealed a conserved binding logic, with strong enhancers being bound in all cellular contexts. Strikingly, although the total number of peaks varied greatly among cell types, these differences were driven by low-occupancy peaks, which mostly do not harbor a consensus p53RE, and are likely explained by cross-linking artifacts.

The use of GRO-seq for identification of p53REs and targets has revealed novel regulatory features that could not be anticipated by other genome-wide studies, and reinforced the notion of p53 as a pioneer factor whose transcriptional activity is restrained by cellular context. Since GRO-seq measures activity of RNA polymerases across the genome, it enables the true measurement of changes in transcription at very short time points (i.e., 30-60 $\mathrm{min}$ ) after p53 activation, and without the need for measuring p53 binding to chromatin, thus preventing the confounding effects of secondary transcriptional events, post-transcriptional regulation, and cross-linking artifacts. The main caveat of the GRO-seq approach is that, if used at longer time points, it is also subject to indirect transcriptional events. This is important because, since p53 is regulated by MDM2 at the level of protein stability, many direct target genes may require elevated p53 protein levels, and thus would not be identified at early time points. Despite this, GROseq analysis at $1 \mathrm{~h}$ post Nutlin treatment, prior to any significant p53 protein accumulation, effectively identified dozens of true direct p53 targets, ${ }^{70}$ indicating that low basal levels of p53 suffice to activate transcription of many of its targets when MDM2 is prevented from masking the $\mathrm{N}$-terminal TADs. Importantly, this early and direct p53 transcriptional program is composed of p53 target genes in multiple downstream effector pathways, including cell cycle arrest, DNA repair, autophagy, metabolism and apoptosis, even in cells that fail to undergo p53-dependent apoptosis. This result supports the concept that the cellular response to p53 activation is not simply defined by differences in the kinetics of arrest versus apoptotic genes.

GRO-seq also readily detects the production of enhancerderived RNAs (eRNAs). Interestingly, even under basal conditions, p53 enhancers associated with direct targets showed elevated levels of eRNAs relative to all other p53 binding events, a sign of enhancer activity or 'priming' prior to Nutlin treatment. Since eRNA production is believed to involve enhancer-promoter looping, ${ }^{97}$ these results indicate that productive p53 enhancers harbor a pre-programmed chromatin conformation conducive to rapid transactivation upon p53 activating stimuli, something that has been confirmed by chromosome conformation capture technology. ${ }^{98-100}$

Unlike most TFs, p53 does not seem to act as part of so-called 'enhanceosomes' composed of multiple TFs binding in a cooperative fashion, but rather functions as a pioneer factor capable of recognizing many of its REs in a variety of contexts, including within 'closed chromatin'. ${ }^{101}$ Several lines of evidence support this notion. First, p53 can recognize many p53REs in the 
context of the nucleosomal chromatin fiber. ${ }^{37,42}$ This was first observed for the p53REs in the p21 locus using in vitro reconstituted chromatin, ${ }^{37}$ confirmed for the $p 21$ locus using cell-based and mononucleosome binding assays, ${ }^{102}$ and later extended to hundreds of canonical p53REs. ${ }^{103}$ At the genome scale, p53 binding is associated with the presence of nucleosomes over the p53RE, ${ }^{101,103}$ and bending of the DNA around the nucleosome increases p53 binding affinity. ${ }^{102-106}$ As expected for a pioneer factor, some studies have found evidence of nucleosome sliding and eviction upon p53 binding. ${ }^{102,103}$ Second, p53 can access hundreds of p53REs in 'closed' chromatin environment. ${ }^{101}$ In fact, p53 ChIP-seq peaks at distal positions within closed chromatin are more likely to have an underlying consensus p53RE than peaks near promoters with active chromatin marks, ${ }^{101}$ which may be explained by enhancer-promoter looping events. Third, p53 binding events that are non-productive in mesenchymal cells, falling within seemingly inaccessible regions of chromatin devoid of marks of active enhancers, become active p53 enhancers in epithelial cells. ${ }^{101}$ This indicates that, regardless of cellular lineage and chromatin context, p53 can bind a set of 'proto-enhancers', which become functional upon changes in the chromatin environment. Altogether, these results indicate that regulatory diversity within the p53 transcriptional program is heavily influenced by mechanisms acting after p53 binding.

\section{Regulatory Diversity in the p53 Network: Life After Binding}

An examination of the recent literature reveals an apparent paradox: p53 binding to chromatin is largely invariant, but the p53-regulated transcriptome is highly variable. As described above, p53 employs an unsophisticated enhancer logic, with a highly conserved pattern of chromatin binding in different cell types and signaling contexts, yet different studies employing ChIP-seq and steady-state RNA measurements have defined largely non-overlapping sets of direct p53 targets in different cell types (reviewed in ref. 72). While some of these differences could be attributed to cross-linking artifacts and miscalling of p53 enhancers, these results likely reveal the existence of mechanisms that modify the p53 transcriptional program after $\mathrm{p} 53$ binding to its enhancers.

Enhancer licensing. Clearly, p53 binding to an enhancer does not suffice to ensure transactivation of the nearest gene. Sammons and colleagues ${ }^{101}$ observed hundreds of p53 proto-enhancers within 'closed chromatin' that were not functional in fibroblasts, yet were associated with p53 signaling in epithelial cells, revealing the presence of an enhancer licensing mechanism. Another member of the p53 family, the p63 isoform $\Delta \mathrm{Np} 63 a$, is highly expressed in the basal layer of all stratified epithelia, where it recognizes the same sequence motif as p53. Accordingly, Sammons et al. hypothesized that $\Delta \mathrm{Np} 63 \mathrm{a}$ may function as a licensing factor for p53 in epithelial cells (Figure 4a). Mechanistically, $\Delta$ Np63a interacts with the SRCAP histone exchange complex, which incorporates the histone variant H2A.Z into chromatin. ${ }^{107,108}$ In turn, H2A.Z serves as an epigenetic modifier that can facilitate gene activation or repression depending on the context by poorly understood mechanisms. ${ }^{109}$ Although a

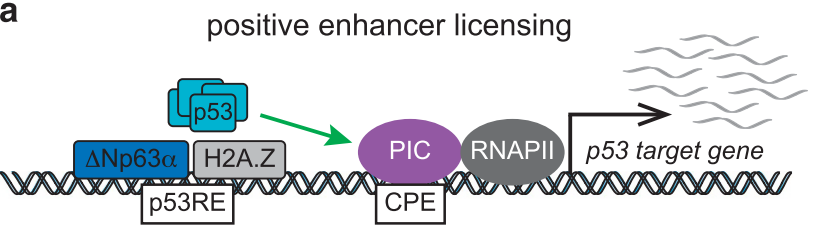

b

repressive promoter methylation

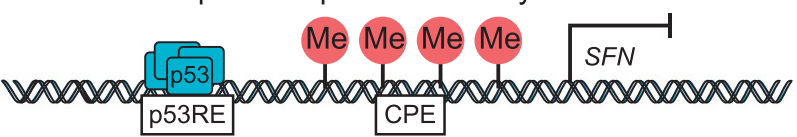

co-operative transcription factor

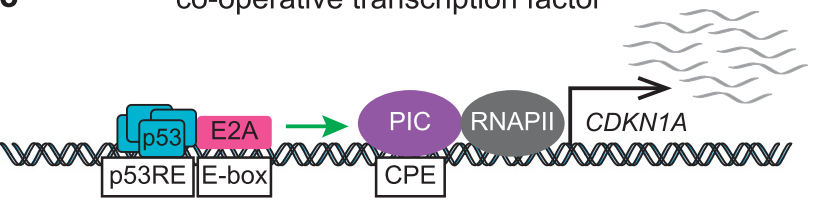

d

repressive insulator / chromatin boundary

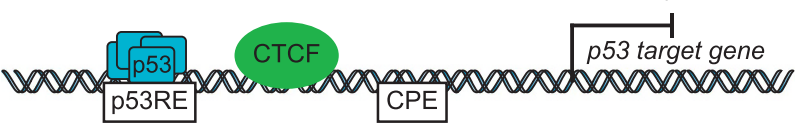

e permissive long-range chromatin interactions
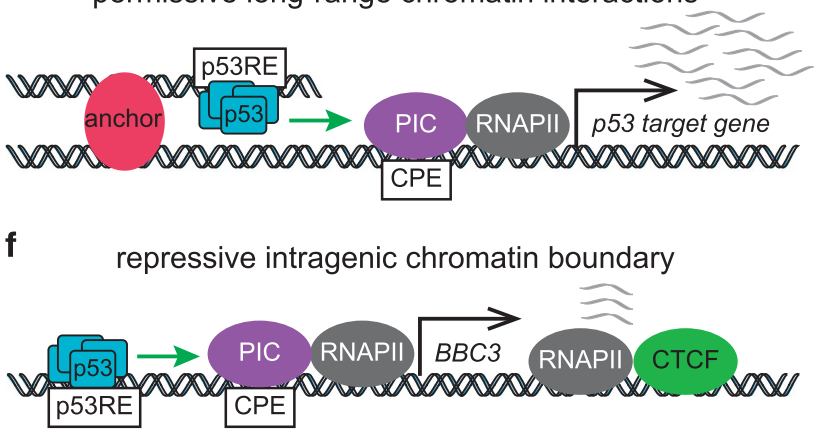

Figure 4 Mechanisms of context-specific regulation of p53 target genes. (a) $\Delta$ Np63 $\alpha$-mediated recruitment of H2A.Z may serve to license some p53 enhancers in epithelial cells. ${ }^{101}$ (b) Methylation of the SFN promoter blocks transactivation by p53 in some cell types. ${ }^{113}$ (c) E2A cooperates with p53 to promote transcription and processing of CDKN1A. ${ }^{119}$ (d) Insulation by CTCF chromatin boundaries in specific cell types could block transactivation of some p53 target genes. (e) Long-range chromatin interactions contribute to activation of some p53 target genes by bringing p53 enhancers into proximity with target gene promoters. (f) An intragenic chromatin boundary marked by CTCF binding prevents transcription of full-length BBC3/PUMA under basal conditions. ${ }^{122} \mathrm{CPE}$, core promoter element; Me, DNA methylation; PIC, preinitiation complex; p53RE, p53 response element; RNAPII, RNA polymerase II

$\triangle \mathrm{Np63a}$ was once thought to function as a dominant negative of p53 through competition for DNA-binding sites, ${ }^{110,111}$ it was later shown that p53 binding to its enhancers is not affected by high endogenous levels of $\Delta N p 63 a$ such as those seen in squamous cell carcinoma cells, where p53 effectively displaced $\Delta \mathrm{Np} 63 \mathrm{a}$, at both functional and non-functional enhancers. ${ }^{107}$ Thus, it is possible to hypothesize that different members of the p53 family, including diverse p53, p63 and p73 isoforms, could modify the repertoire of 'licensed' p53 enhancers across the genome, by recruiting chromatin modifying, remodeling or looping factors, with either negative or positive impacts on p53-dependent transactivation. 
Promoter responsiveness. The qualifying impact of target promoters on the p53 transcriptional program cannot be understated. If a target promoter is silenced by CpG DNA methylation, p53 binding to a nearby enhancer could not possibly induce transcription. In fact, the impact of DNA methylation on p53 transactivation was clearly demonstrated for SFN (14-3-3б, stratifin), a key direct p53 target gene involved in cell cycle arrest, ${ }^{112}$ which is commonly silenced by this mechanism in many normal and cancer cell types (Figure 4b). In one study, p53 activation by Nutlin led to p53 binding and p53-induced histone acetylation at the SFN upstream region in different cell types, yet p53 binding was unproductive in those cell types where the locus was methylated. ${ }^{113}$ As would be expected, expression of 14-3$3 \sigma$ in cells where the promoter is methylated is upregulated by inhibitors of DNA methylation. ${ }^{114}$ Clearly, as the global pattern of promoter DNA methylation changes in different cell lineages, and during tumor evolution, so too could the direct p53 transcriptional program, even if p53 enhancer binding is conserved.

The 'responsiveness' of a p53 target promoter can be also qualified by its core promoter elements (CPEs), the DNA sequences required for recruitment of general transcription factors (GTFs) and consequent assembly of the PIC (reviewed in ref. 115). The impact of varying CPEs on regulation of different p53 targets was clearly established by Morachis et al. ${ }^{116}$ Earlier work established that p53 target promoters display pronounced differences in RNAPII occupancy prior to p53 activation, with higher levels observed at cell cycle arrest genes (e.g., $C D K N 1 A$ ) relative to apoptotic genes (e.g., FAS and $B B C 3$ ), which correlated with a delayed in the accumulation of mature FAS mRNAs. ${ }^{117}$ To investigate the mechanisms driving these differences, Morachis and colleagues employed in vitro transcription assays to define the contributions of the underlying CPEs. ${ }^{116}$ They found that the CDKN1A core promoter drives rapid TATA box-dependent PIC assembly, but permits few rounds of RNAPII re-initiation. Conversely, the FAS core promoter is inefficient in terms of assembly but supports multiple rounds of re-initiation. Further analysis revealed the presence of a nuclear transcription factor $Y$ (NF-Y) response element required for basal transcription of FAS, but not CDKN1A, in vivo. These observations are consistent with studies showing rapid ( $<30 \mathrm{~min}$ ) inactivation of CDKN1A transcription upon removal of Nutlin from cell cultures, yet delayed inactivation of $F A S .{ }^{118}$ Using a genomewide shRNA screening strategy to identify gene-specific coregulators of p21 and PUMA after p53 activation by Nutlin, Andrysik et al. ${ }^{119}$ identified the DNA-binding protein E2A (also known as TCF3) as a gene-specific cofactor at the CDKN1A locus, which also functions as a repressor of PUMA expression. Depletion of E2A leads to an increase in the PUMA/p21 expression ratio without affecting p53 binding to the enhancers at either locus, leading to a switch in the response to Nutlin, from cell cycle arrest to apoptosis. ${ }^{119}$ Although E2A was shown to bind the CDKN1A core promoter, E2A depletion did not affect the ability of p53 to stimulate RNAPII elongation, suggesting a requirement for E2A for efficient p21 mRNA processing (Figure 4c). Thus, DNA-encoded features at diverse core promoters can pre-program the transcriptional output elicited by p53 activation.
Chromatin topology. High-throughput measurements of chromatin topology (e.g., 4C, Hi-C), have made clear that chromosomes are organized into topologically associating domains, which are regions of DNA within which physical interactions occur frequently, while interactions across domain boundaries are more infrequent. ${ }^{120}$ This organization restrains the action of enhancers and TFs to target genes within a domain. It is clear that these chromatin territories vary greatly across cell lineages, and that chromatin organizing factors such as CTCF and cohesins contribute to their formation ${ }^{120}$ (Figure 4d). How could these domains impact the ability of p53 to activate its target genes? It is possible that even if $\mathrm{p} 53$ enhancer binding is conserved, the creation of a domain boundary between a distal enhancer and the target promoter could impede transactivation. Thus, cell type-specific chromatin topologies could restrict the set of p53 targets available for direct transactivation, even in the absence of DNA methylation or other silencing mechanisms. Recently, studies of Drosophila p53 provided in vivo evidence of long-range interactions between a p53 enhancer and multiple targets in cis within a large genomic region $(>300 \mathrm{~kb})$ containing the apoptotic target gene Reaper ${ }^{99}$ (Figure 4e). In this study, it was noted that the chromatin configuration of this locus was unaffected by p53 status or DNA damage, supporting the notion of a 'pre-programmed' chromatin architecture. $^{99}$ In human cells, Agami and colleagues $^{100}$ identified distal p53 enhancers that interacted intra-chromosomally with multiple distant genes in cis to confer p53-dependent regulation. Using 4C, they mapped the interaction between these distal enhancers and multiple target loci, and determined that these 'chromatin loops' were not dependent on p53, but rather represented pre-existing chromatin architectures.

Systematic examination of the relationship among p53 binding, gene expression, histone methylation, chromatin accessibility, and p53RE sequence in untransformed human cells revealed that the inducible expression of p53 targets correlates with the steady-state chromatin landscape. ${ }^{121}$ In this study, the most highly-inducible p53 targets were marked by repressive histone modifications or CTCF binding, suggesting a dampening effect of repressive chromatin architecture on $\mathrm{p} 53$ responsiveness. In fact, studies of the $B B C 3$ locus revealed the action of CTCF and cohesin as gene-specific repressors within the p53 program ${ }^{122}$ (Figure $4 \mathrm{f}$ ). The $B B C 3$ locus harbors an intragenic chromatin boundary delimited by CTCF and cohesin binding, and sharp changes in histone modifications. Under conditions of basal p53 activity, RNAPII transcribes the region upstream of the boundary to produce non-coding RNAs. Upon p53 stimulation, RNAPII transcribes past the boundary to produce full-length, PUMA-encoding mRNAs. Interestingly, when CTCF or cohesin are depleted, PUMA is upregulated without p53 activation or induction of other p53 targets, suggesting that the chromatin boundary plays a repressive role, in a gene-specific manner.

Altogether, these results reveal a wealth of regulatory mechanisms that can modify the transcriptional output elicited by $\mathrm{p} 53$ activation without necessarily modulating p53 binding to chromatin. 
Future perspectives. Despite tremendous advances in our understanding of p53 function as a transcriptional regulator, there are still some major open questions.

How does p53 function in different tissues within the human body? To date, most knowledge about p53 action is based on cell culture studies and mouse models, two experimental systems that introduce important variables that could modify p53 activity in significant ways. With new technological advances, it is possible to envision the study of p53 in human tissues with minimal or no culture. For example, different blood cell types could be isolated to investigate p53 chromatin binding, transactivation, and indirect regulation in different cell lineages ex vivo. Such human research studies could address a plethora of additional questions. For example, what is the impact of biological variables such as sex, age, ethnicity, circadian rhythm, or metabolic state on the p53 transcriptional program? These studies could potentially reveal variations in p53 signaling of importance for our understanding of its tumor suppressive activity. As clinical trials for various MDM2 inhibitors continue to advance, it would be possible to investigate the impact of specific p53 activation on various normal human tissues, not just the target tumor tissue, as well as normal human physiology.

What are the key p53 target genes and effectors pathways mediating tumor suppression in different human tissues? This is a major unresolved question in the field. Canonical effector pathways such as cell cycle arrest, senescence, and apoptosis have been shown to be dispensable for tumor suppression in some settings. ${ }^{123}$ As discussed above, it is possible that p53 employs different target genes and effector pathways in different contexts, but it is also possible that p53 activates a highly redundant transcriptional program where no single target gene harbors a significant portion of the overall tumor suppressive activity. Answering this question would not only advance our understanding of tumor biology, but also pave the road for better p53-based cancer therapies.

Finally, how could p53 tumor suppression function be enhanced for therapeutic purposes via manipulation of its transcriptional coactivators, target genes or chromatin environment? Most likely, the many MDM2 inhibitors being tested in clinical trials will fail as mono-therapies, due to the fact that they induce reversible cell cycle arrest in most cancer cell types, and that they produce hematological toxicity over prolonged treatment. However, their efficacy could be improved via combinatorial approaches that modify the activity of key p53 cofactors or target genes, or even perhaps the chromatin environment, to facilitate a stronger tumor suppressive response while minimizing toxicity. Clearly, much additional research in this area is required to serve the millions of cancer patients worldwide who could benefit from therapeutic re-activation of $\mathrm{p} 53$.

\section{Conflict of Interest}

The authors declare no conflict of interest.

1. Fields $S$, Jang SK. Presence of a potent transcription activating sequence in the $p 53$ protein. Science 1990; 249: 1046-1049.

2. Raycroft L, Wu HY, Lozano G. Transcriptional activation by wild-type but not transforming mutants of the p53 anti-oncogene. Science 1990; 249: 1049-1051.

3. Kern SE, Kinzler KW, Bruskin A, Jarosz D, Friedman P, Prives C et al. Identification of p53 as a sequence-specific DNA-binding protein. Science 1991; 252: 1708-1711.
4. Farmer G, Bargonetti J, Zhu H, Friedman P, Prywes R, Prives $\mathrm{C}$. Wild-type $\mathrm{p} 53$ activates transcription in vitro. Nature 1992; 358: 83-86.

5. Foord OS, Bhattacharya $P$, Reich Z, Rotter VA. DNA binding domain is contained in the C-terminus of wild type p53 protein. Nucleic Acids Res 1991; 19: 5191-5198.

6. el-Deiry WS, Kern SE, Pietenpol JA, Kinzler KW, Vogelstein B. Definition of a consensus binding site for p53. Nat Genet 1992; 1: 45-49.

7. Oliner JD, Pietenpol JA, Thiagalingam S, Gyuris J, Kinzler KW, Vogelstein B. Oncoprotein MDM2 conceals the activation domain of tumour suppressor p53. Nature 1993; 362 : 857-860.

8. Kussie PH, Gorina S, Marechal V, Elenbaas B, Moreau J, Levine AJ et al. Structure of the MDM2 Oncoprotein Bound to the p53 Tumor Suppressor Transactivation Domain. Science 1996; 274: 948-953.

9. Kubbutat MH, Jones SN, Vousden KH. Regulation of p53 stability by Mdm2. Nature 1997; 387: 299-303.

10. Riemenschneider MJ, Buschges R, Wolter M, Reifenberger J, Bostrom J, Kraus JA et al. Amplification and overexpression of the MDM4 (MDMX) gene from 1q32 in a subset of malignant gliomas without TP53 mutation or MDM2 amplification. Cancer Res 1999; 59 : 6091-6096.

11. Parant J, Chavez-Reyes A, Little NA, Yan W, Reinke V, Jochemsen AG et al. Rescue of embryonic lethality in Mdm4-null mice by loss of Trp53 suggests a nonoverlapping pathway with MDM2 to regulate p53. Nat Genet 2001; 29: 92-95.

12. Vousden KH, Prives C. Blinded by the Light: The Growing Complexity of p53. Cell 2009; 137: 413-431.

13. Candau R, Scolnick DM, Darpino P, Ying CY, Halazonetis TD, Berger SL. Two tandem and independent sub-activation domains in the amino terminus of p53 require the adaptor complex for activity. Oncogene 1997; 15: 807-816.

14. Venot C, Maratrat M, Sierra V, Conseiller E, Debussche L. Definition of a p53 transactivation function-deficient mutant and characterization of two independent p53 transactivation subdomains. Oncogene 1999; 18: 2405-2410.

15. Zhu J, Zhou W, Jiang J, Chen X. Identification of a novel p53 functional domain that is necessary for mediating apoptosis. J Biol Chem 1998; 273: 13030-13036.

16. Brady CA, Jiang D, Mello SS, Johnson TM, Jarvis LA, Kozak MM et al. Distinct p53 transcriptional programs dictate acute DNA-damage responses and tumor suppression. Cell 2011; 145: 571-583.

17. Lee KC, Crowe AJ, Barton MC. p53-mediated repression of alpha-fetoprotein gene expression by specific DNA binding. Mol Cell Biol 1999; 19: 1279-1288.

18. Murphy M, Ahn J, Walker KK, Hoffman WH, Evans RM, Levine AJ et al. Transcriptional repression by wild-type p53 utilizes histone deacetylases, mediated by interaction with mSin3a. Genes Dev 1999; 13: 2490-2501.

19. Zhao R, Gish K, Murphy M, Yin Y, Notterman D, Hoffman WH et al. Analysis of p53regulated gene expression patterns using oligonucleotide arrays. Genes Dev 2000; 14 : 981-993.

20. Ogden SK, Lee KC, Wernke-Dollries K, Stratton SA, Aronow B, Barton MC. p53 targets chromatin structure alteration to repress alpha-fetoprotein gene expression. $\mathrm{J}$ Biol Chem 2001; 276: 42057-42062.

21. Wu Y, Mehew JW, Heckman CA, Arcinas M, Boxer LM. Negative regulation of bcl-2 expression by p53 in hematopoietic cells. Oncogene 2001; 20: 240-251.

22. Wilkinson DS, Tsai WW, Schumacher MA, Barton MC. Chromatin-bound p53 anchors activated Smads and the mSin3A corepressor to confer transforming growth factor betamediated transcription repression. Mol Cell Biol 2008; 28: 1988-1998.

23. Chipuk JE, Green DR. Dissecting p53-dependent apoptosis. Cell Death Differ 2006; 13: 994-1002.

24. Jiang D, Brady CA, Johnson TM, Lee EY, Park EJ, Scott MP et al. Full p53 transcriptional activation potential is dispensable for tumor suppression in diverse lineages. Proc Nat Acad Sci USA 2011; 108: 17123-17128.

25. Soussi T, Kato S, Levy PP, Ishioka C. Reassessment of the TP53 mutation database in human disease by data mining with a library of TP53 missense mutations. Hum Mutat2005; 25: 6-17.

26. Laptenko $\mathrm{O}$, Prives $\mathrm{C}$. Transcriptional regulation by $p 53$ : one protein, many possibilities. Cell Death Differ 2006; 13: 951-961.

27. Beckerman R, Prives C. Transcriptional regulation by p53. Cold Spring Harb Perspect Biol 2010; 2: $a 000935$

28. Raj N, Attardi LD. The Transactivation Domains of the p53 Protein. Cold Spring Harb Perspect Med 2017; 7: a026047.

29. Hupp TR, Meek DW, Midgley CA, Lane DP. Regulation of the specific DNA binding function of p53. Cell 1992; 71: 875-886.

30. Gu W, Roeder RG. Activation of $p 53$ sequence-specific DNA binding by acetylation of the p53 C-terminal domain. Cell 1997; 90: 595-606.

31. Abarzua P, LoSardo JE, Gubler ML, Neri A. Microinjection of monoclonal antibody PAb421 into human SW480 colorectal carcinoma cells restores the transcription activation function to mutant p53. Cancer Res 1995; 55: 3490-3494.

32. Hupp TR, Lane DP. Allosteric activation of latent p53 tetramers. Curr Biol 1994; 4 : 865-875.

33. Anderson ME, Woelker B, Reed M, Wang P, Tegtmeyer P. Reciprocal interference between the sequence-specific core and nonspecific C-terminal DNA binding domains of p53: implications for regulation. Mol Cell Biol 1997; 17: 6255-6264. 
34. Hupp TR, Sparks A, Lane DP. Small peptides activate the latent sequence-specific DNA binding function of p53. Cell 1995; 83: 237-245.

35. Selivanova G, lotsova V, Okan I, Fritsche M, Strom M, Groner B et al. Restoration of the growth suppression function of mutant $\mathrm{p} 53$ by a synthetic peptide derived from the p53 C-terminal domain. Nat Med 1997; 3: 632-638.

36. Selivanova G, Ryabchenko L, Jansson E, lotsova V, Wiman KG. Reactivation of mutant p53 through interaction of a C-terminal peptide with the core domain. Mol Cell Biol 1999; 19: 3395-3402.

37. Espinosa JM, Emerson BM. Transcriptional regulation by p53 through intrinsic DNA chromatin binding and site-directed cofactor recruitment. Mol Cell 2001; 8: 57-69.

38. Kaeser MD, lggo RD. Chromatin immunoprecipitation analysis fails to support the latency model for regulation of p53 DNA binding activity in vivo. Proc Natl Acad Sci USA 2002; 99 : 95-100.

39. McKinney $\mathrm{K}$, Prives $\mathrm{C}$. Efficient specific DNA binding by $\mathrm{p} 53$ requires both its central and $\mathrm{C}$-terminal domains as revealed by studies with high-mobility group 1 protein. Mol Cell Biol 2002; 22: 6797-6808.

40. Gohler T, Reimann M, Cherny D, Walter K, Warnecke G, Kim E et al. Specific interaction of p53 with target binding sites is determined by DNA conformation and is regulated by the C-terminal domain. J Biol Chem 2002; 277: 41192-41203.

41. Ayed A, Mulder FA, Yi GS, Lu Y, Kay LE, Arrowsmith CH. Latent and active p53 are identical in conformation. Nat Struct Biol 2001; 8: 756-760.

42. Kim H, Kim K, Choi J, Heo K, Baek HJ, Roeder RG et al. p53 requires an intact C-terminal domain for DNA binding and transactivation. J Mol Biol 2012; 415: 843-854.

43. Hamard PJ, Lukin DJ, Manfredi JJ. p53 basic $\mathrm{C}$ terminus regulates p53 functions through DNA binding modulation of subset of target genes. J Biol Chem 2012; 287: 22397-22407.

44. McKinney K, Mattia M, Gottifredi V, Prives C. p53 linear diffusion along DNA requires its $\mathrm{C}$ terminus. Mol Cell 2004; 16: 413-424.

45. Tafvizi A, Huang F, Fersht AR, Mirny LA, van Oijen AM. A single-molecule characterization of p53 search on DNA. Proc Natl Acad Sci USA 2011; 108: 563-568.

46. Tafvizi A, Huang F, Leith JS, Fersht AR, Mirny LA, van Oijen AM. Tumor suppressor p53 slides on DNA with low friction and high stability. Biophys J 2008; 95: L01-L03.

47. Khazanov N, Levy Y. Sliding of $p 53$ along DNA can be modulated by its oligomeric state and by cross-talks between its constituent domains. J Mol Biol 2011; 408: 335-355.

48. Friedler A, Veprintsev DB, Freund SM, von Glos KI, Fersht AR. Modulation of binding of DNA to the C-terminal domain of p53 by acetylation. Structure 2005; 13: 629-636.

49. Laptenko O, Shiff I, Freed-Pastor W, Zupnick A, Mattia M, Freulich E et al. The p53 C terminus controls site-specific DNA binding and promotes structural changes within the central DNA binding domain. Mol Cell 2015; 57: 1034-1046.

50. Feng L, Lin T, Uranishi H, Gu W, Xu Y. Functional analysis of the roles of posttranslational modifications at the p53 C terminus in regulating p53 stability and activity. Mol Cell Biol 2005; 25: 5389-5395.

51. Krummel KA, Lee CJ, Toledo F, Wahl GM. The C-terminal lysines fine-tune P53 stress responses in a mouse model but are not required for stability control or transactivation. Proc Natl Acad Sci USA 2005; 102: 10188-10193.

52. Simeonova I, Jaber S, Draskovic I, Bardot B, Fang M, Bouarich-Bourimi R et al. Mutant mice lacking the p53 C-terminal domain model telomere syndromes. Cell Rep 2013; 3 ; 2046-2058.

53. Hamard PJ, Barthelery N, Hogstad B, Mungamuri SK, Tonnessen CA, Carvajal LA et al. The $C$ terminus of $p 53$ regulates gene expression by multiple mechanisms in a target- and tissue-specific manner in vivo. Genes Dev 2013; 27: 1868-1885.

54. Poyurovsky MV, Katz C, Laptenko O, Beckerman R, Lokshin M, Ahn J et al. The C terminus of p53 binds the N-terminal domain of MDM2. Nat Struct Mol Biol 2010; 17: 982-989.

55. Fuxreiter M, Tompa P, Simon I, Uversky VN, Hansen JC, Asturias FJ. Malleable machines take shape in eukaryotic transcriptional regulation. Nat Chem Biol 2008; 4: 728-737.

56. Rustandi RR, Baldisseri DM, Weber DJ. Structure of the negative regulatory domain of $\mathrm{p} 53$ bound to S100B(betabeta). Nat Struct Biol 2000; 7: 570-574.

57. Mujtaba S, He Y, Zeng L, Yan S, Plotnikova O, Sachchidanand et al. Structural mechanism of the bromodomain of the coactivator CBP in $\mathrm{p53}$ transcriptional activation. Mol Cell 2004 13: 251-263.

58. Tong Q, Mazur SJ, Rincon-Arano H, Rothbart SB, Kuznetsov DM, Cui G et al. An acetylmethyl switch drives a conformational change in $\mathrm{p} 53$. Structure 2015; 23: 322-331.

59. Avalos JL, Celic I, Muhammad S, Cosgrove MS, Boeke JD, Wolberger C. Structure of a Sir2 enzyme bound to an acetylated p53 peptide. Mol Cell 2002; 10: 523-535.

60. Chuikov S, Kurash JK, Wilson JR, Xiao B, Justin N, Ivanov GS et al. Regulation of p53 activity through lysine methylation. Nature 2004; 432: 353-360.

61. Lowe ED, Tews I, Cheng KY, Brown NR, Gul S, Noble ME et al. Specificity determinants of recruitment peptides bound to phospho-CDK2/cyclin A. Biochemistry 2002; 41: 15625-15634.

62. Kannan S, Lane DP, Verma CS. Long range recognition and selection in IDPs: the interactions of the C-terminus of p53. Sci Rep 2016; 6: 23750.

63. Drane P, Barel M, Balbo M, Frade R. Identification of RB18A, a 205 kDa new p53 regulatory protein which shares antigenic and functional properties with p53. Oncogene 1997; 15 3013-3024.

64. Barlev NA, Liu L, Chehab NH, Mansfield K, Harris KG, Halazonetis TD et al. Acetylation of p53 activates transcription through recruitment of coactivators/histone acetyltransferases. Mol Cell 2001; 8: 1243-1254.

65. Kato M, McKnight SL. Cross-beta Polymerization of Low Complexity Sequence Domains. Cold Spring Harb Perspect Biol 2017; 9: a023598.
66. Kwon I, Kato M, Xiang S, Wu L, Theodoropoulos P, Mirzaei H et al. Phosphorylationregulated binding of RNA polymerase II to fibrous polymers of low-complexity domains. Cell 2013; 155: 1049-1060.

67. Laptenko O, Tong DR, Manfredi J, Prives $\mathrm{C}$. The tail that wags the dog: how the disordered C-terminal domain controls the transcriptional activities of the p53 tumor-suppressor protein. Trends Biochem Sci 2016; 41: 1022-1034.

68. Ginsberg D, Mechta F, Yaniv M, Oren M. Wild-type p53 can down-modulate the activity of various promoters. Proc Natl Acad Sci USA 1991; 88: 9979-9983.

69. Tonelli C, Morelli MJ, Sabo A, Verrecchia A, Rotta L, Capra T et al. Genome-wide analysis of p53-regulated transcription in Myc-driven lymphomas. Oncogene 2017; 36: 2921-2929.

70. Allen MA, Andrysik Z, Dengler VL, Mellert HS, Guarnieri A, Freeman JA et al. Global analysis of p53-regulated transcription identifies its direct targets and unexpected regulatory mechanisms. Elife 2014; 3 : $\mathrm{e} 02200$.

71. Fischer $\mathrm{M}$, Steiner $\mathrm{L}$, Engeland $\mathrm{K}$. The transcription factor $\mathrm{p} 53$ : not a repressor, solely an activator. Cell Cycle 2014; 13: 3037-3058.

72. Fischer M. Census and evaluation of p53 target genes. Oncogene 2017; 36: 3943-3956.

73. Johnson RA, Ince TA, Scotto KW. Transcriptional repression by p53 through direct binding to a novel DNA element. J Biol Chem 2001; 276: 27716-27720.

74. Wang B, Xiao Z, Ren EC. Redefining the p53 response element. Proc Natl Acad Sci USA 2009; 106: 14373-14378.

75. Li M, He Y, Dubois W, Wu X, Shi J, Huang J. Distinct regulatory mechanisms and functions for p53-activated and p53-repressed DNA damage response genes in embryonic stem cells. Mol Cell 2012; 46: 30-42.

76. Verfaillie A, Svetlichnyy D, Imrichova H, Davie K, Fiers M, Kalender Atak Z et al. Multiplex enhancer-reporter assays uncover unsophisticated TP53 enhancer logic. Genome Res 2016; 26: 882-895

77. Harper JW, Adami GR, Wei N, Keyomarsi K, Elledge SJ. The p21 Cdk-interacting protein Cip1 is a potent inhibitor of G1 cyclin-dependent kinases. Cell 1993; 75: 805-816.

78. el-Deiry WS, Tokino T, Velculescu VE, Levy DB, Parsons R, Trent JM et al. WAF1, a potential mediator of p53 tumor suppression. Cell 1993; 75: 817-825.

79. Benson EK, Mungamuri SK, Attie O, Kracikova M, Sachidanandam R, Manfredi JJ et al. p53-dependent gene repression through p21 is mediated by recruitment of E2F4 repression complexes. Oncogene 2014; 33: 3959-3969.

80. Quaas M, Muller GA, Engeland K. p53 can repress transcription of cell cycle genes through a p21(WAF1/CIP1)-dependent switch from MMB to DREAM protein complex binding at CHR promoter elements. Cell Cycle 2012; 11: 4661-4672.

81. Fischer M, Quaas M, Nickel A, Engeland K. Indirect p53-dependent transcriptional repression of Survivin, CDC25C, and PLK1 genes requires the cyclin-dependent kinase inhibitor $21 /$ CDKN1A and CDE/CHR promoter sites binding the DREAM complex. Oncotarget 2015; 6: 41402-41417.

82. Fischer M, Quaas M, Steiner L, Engeland K. The p53-p21-DREAM-CDE/CHR pathway regulates G2/M cell cycle genes. Nucleic Acids Res 2016; 44: 164-174.

83. Carvajal LA, Hamard PJ, Tonnessen C, Manfredi JJ. E2F7, a novel target, is up-regulated by p53 and mediates DNA damage-dependent transcriptional repression. Genes Dev 2012; 26: 1533-1545.

84. Aksoy O, Chicas A, Zeng T, Zhao Z, McCurrach M, Wang X et al. The atypical E2F family member E2F7 couples the p53 and RB pathways during cellular senescence. Genes Dev 2012; 26: 1546-1557.

85. Chang TC, Wentzel EA, Kent OA, Ramachandran K, Mullendore M, Lee KH et al. Transactivation of miR-34a by p53 broadly influences gene expression and promotes apoptosis. Mol Cell 2007; 26: 745-752.

86. Raver-Shapira N, Marciano E, Meiri E, Spector Y, Rosenfeld N, Moskovits N et al. Transcriptional activation of miR-34a contributes to p53-mediated apoptosis. Mol Cell 2007; 26: $731-743$.

87. Tarasov V, Jung P, Verdoodt B, Lodygin D, Epanchintsev A, Menssen A et al. Differential regulation of microRNAs by p53 revealed by massively parallel sequencing: miR-34a is a p53 target that induces apoptosis and G(1)-arrest. Cell Cycle 2007; 6 : 1586-1593

88. Tazawa $\mathrm{H}$, Tsuchiya N, Izumiya M, Nakagama $\mathrm{H}$. Tumor-suppressive miR-34a induces senescence-like growth arrest through modulation of the E2F pathway in human colon cancer cells. Proc Natl Acad Sci USA 2007; 104: 15472-15477.

89. Lal A, Thomas MP, Altschuler G, Navarro F, O'Day E, Li XL et al. Capture of microRNAbound mRNAs identifies the tumor suppressor miR-34a as a regulator of growth factor signaling. PLoS Genet 2011; 7: e1002363.

90. Hoffman $Y$, Pilpel $Y$, Oren M. microRNAs and Alu elements in the p53-Mdm2-Mdm4 regulatory network. J Mol Cell Biol 2014; 6: 192-197.

91. Thut CJ, Goodrich JA, Tjian R. Repression of p53-mediated transcription by MDM2: a dual mechanism. Genes Dev 1997; 11: 1974-1986.

92. White DE, Talbott KE, Arva NC, Bargonetti J. Mouse double minute 2 associates with chromatin in the presence of $\mathrm{p} 53$ and is released to facilitate activation of transcription. Cancer Res 2006; 66: 3463-3470.

93. Ohkubo S, Tanaka T, Taya Y, Kitazato K, Prives C. Excess HDM2 impacts cell cycle and apoptosis and has a selective effect on p53-dependent transcription. J Biol Chem 2006; 281: 16943-16950. 
94. Biderman L, Manley JL, Prives C. Mdm2 and MdmX as regulators of gene expression. Genes Cancer 2012; 3: 264-273.

95. Menendez D, Nguyen TA, Freudenberg JM, Mathew VJ, Anderson CW, Jothi R et al. Diverse stresses dramatically alter genome-wide p53 binding and transactivation landscape in human cancer cells. Nucleic Acids Res 2013; 41: 7286-7301.

96. Wei CL, Wu Q, Vega VB, Chiu KP, Ng P, Zhang T et al. A global map of p53 transcriptionfactor binding sites in the human genome. Cell 2006; 124: 207-219.

97. Li W, Notani D, Rosenfeld MG. Enhancers as non-coding RNA transcription units: recent insights and future perspectives. Nat Rev Genet 2016; 17: 207-223.

98. Link N, Abrams JM. DNA loops specify p53 network responses. Cell Cycle 2014; 13: 1659.

99. Link N, Kurtz P, O'Neal M, Garcia-Hughes G, Abrams JM. A p53 enhancer region regulates target genes through chromatin conformations in cis and in trans. Genes Dev 2013; 27: 2433-2438.

100. Melo CA, Drost J, Wijchers PJ, van de Werken $\mathrm{H}$, de Wit E, Oude Vrielink JA et al. eRNAs are required for p53-dependent enhancer activity and gene transcription. Mol Cell 2013; 49: 524-535.

101. Sammons MA, Zhu J, Drake AM, Berger SL. TP53 engagement with the genome occurs in distinct local chromatin environments via pioneer factor activity. Genome Res 2015; 25: 179-188.

102. Laptenko O, Beckerman R, Freulich E, Prives C. p53 binding to nucleosomes within the p21 promoter in vivo leads to nucleosome loss and transcriptional activation. Proc Natl Acad Sci USA 2011; 108: 10385-10390.

103. Lidor Nili E, Field Y, Lubling Y, Widom J, Oren M, Segal E. p53 binds preferentially to genomic regions with high DNA-encoded nucleosome occupancy. Genome Res 2010; 20: 1361-1368.

104. Nagaich AK, Zhurkin VB, Durell SR, Jernigan RL, Appella E, Harrington RE. p53-induced DNA bending and twisting: p53 tetramer binds on the outer side of a DNA loop and increases DNA twisting. Proc Natl Acad Sci USA 1999; 96: 1875-1880.

105. Sahu G, Wang D, Chen CB, Zhurkin VB, Harrington RE, Appella E et al. p53 binding to nucleosomal DNA depends on the rotational positioning of DNA response element. J Biol Chem 2010; 285: 1321-1332.

106. Cui $F$, Zhurkin VB. Rotational positioning of nucleosomes facilitates selective binding of p53 to response elements associated with cell cycle arrest. Nucleic Acids Res 2014; 42: 836-847.

107. Gallant-Behm CL, Ramsey MR, Bensard CL, Nojek I, Tran J, Liu M et al. DeltaNp63alpha represses anti-proliferative genes via H2A.Z deposition. Genes Dev 2012; 26: 2325-2336.

108. Gallant-Behm CL, Espinosa JM. DeltaNp63alpha utilizes multiple mechanisms to repress transcription in squamous cell carcinoma cells. Cell Cycle 2013; 12: 409-416.

109. Zlatanova J, Thakar A. H2A.Z: view from the top. Structure 2008; 16: 166-179.

110. Mundt HM, Stremmel W, Melino G, Krammer PH, Schilling T, Muller M. Dominant negative (DeltaN) p63alpha induces drug resistance in hepatocellular carcinoma by interference with apoptosis signaling pathways. Biochem Biophys Res Commun 2010; 396: 335-341.

111. Yang A, Kaghad M, Wang Y, Gillett E, Fleming MD, Dotsch V et al. p63, a p53 homolog at 3q27-29, encodes multiple products with transactivating, death-inducing, and dominantnegative activities. Mol Cell 1998; 2: 305-316.
112. Hermeking $\mathrm{H}$, Lengauer $\mathrm{C}$, Polyak $\mathrm{K}$, He TC, Zhang $\mathrm{L}$, Thiagalingam $\mathrm{S}$ et al. 14-3-3 sigma is a p53-regulated inhibitor of G2/M progression. Mol Cell 1997; 1: 3-11.

113. Paris R, Henry RE, Stephens SJ, McBryde M, Espinosa JM. Multiple p53-independent gene silencing mechanisms define the cellular response to p53 activation. Cell Cycle 2008; 7: 2427-2433.

114. Ferguson AT, Evron E, Umbricht $\mathrm{CB}$, Pandita TK, Chan TA, Hermeking $\mathrm{H}$ et al. High frequency of hypermethylation at the 14-3-3 sigma locus leads to gene silencing in breast cancer. Proc Natl Acad Sci USA 2000; 97: 6049-6054.

115. Gomes NP, Espinosa JM. Differential regulation of $p 53$ target genes: it's (core promoter) elementary. Genes Dev 2010; 24: 111-114.

116. Morachis JM, Murawsky CM, Emerson BM. Regulation of the $\mathrm{p} 53$ transcriptional response by structurally diverse core promoters. Genes Dev 2010; 24: 135-147.

117. Espinosa JM, Verdun RE, Emerson BM. p53 functions through stress- and promoterspecific recruitment of transcription initiation components before and after DNA damage. Mol Cell 2003; 12: 1015-1027.

118. Gomes NP, Espinosa JM. Disparate chromatin landscapes and kinetics of inactivation impact differential regulation of p53 target genes. Cell Cycle 2010; 9: 3428-3437.

119. Andrysik Z, Kim J, Tan AC, Espinosa JM. A genetic screen identifies TCF3/E2A and TRIAP1 as pathway-specific regulators of the cellular response to p53 activation. Cell Rep 2013: 3: 1346-1354

120. Matharu N, Ahituv N. Minor loops in major folds: enhancer-promoter looping, chromatin restructuring, and their association with transcriptional regulation and disease. PLoS Genet 2015; 11: e1005640.

121. Su D, Wang X, Campbell MR, Song L, Safi A, Crawford GE et al. Interactions of chromatin context, binding site sequence content, and sequence evolution in stress-induced p53 occupancy and transactivation. PLoS Genet 2015; 11: e1004885.

122. Gomes NP, Espinosa JM. Gene-specific repression of the p53 target gene PUMA via intragenic CTCF-Cohesin binding. Genes Dev 2010; 24: 1022-1034.

123. Bieging KT, Mello SS, Attardi LD. Unravelling mechanisms of p53-mediated tumour suppression. Nat Rev Cancer 2014; 14: 359-370.

(i) $(-)$ This work is licensed under a Creative Commons Attribution-NonCommercial-NoDerivs 4.0 International License. The images or other third party material in this article are included in the article's Creative Commons license, unless indicated otherwise in the credit line; if the material is not included under the Creative Commons license, users will need to obtain permission from the license holder to reproduce the material. To view a copy of this license, visit http://creativecommons.org/licenses/by-nc-nd/4.0/

C) The Author(s) 2018 